\title{
Del Chavalonco al Programa IVX (Screening Genometabólico) en Pediatría
}

\author{
FRANCISCO BARRERA Q. ${ }^{1}$ \\ 1. Médico Pediatra, Complejo Hospitalario San Borja Arriarán.
}

"La ciencia, la caridad, la beneficencia, la higiene, los hospitales, los asilos, las maravillas y las barbaridades de nuestros mayores en materia de médicos y de medicina".

Extraído de la portada de: Médicos de antaño.

Benjamín Vicuña Mackenna. Primera edición 1877.

Cuando Don Pedro de Valdivia vino a conocer en 1941 el "mal famado país de Chile", trajo consigo clérigos, frailes, capellanes, alarifes, gallinas, una mujer, escribanos, cerdos, secretarios de carta. Previo a su llegada, Hernando de Magallanes había descubierto Chile por el Sur en el año 1520 y Diego de Almagro por el Norte en 1535. Sin embargo, a Don Pedro no le acompañó ni un solo médico, ni siquiera un sangrador. Omisión lógica para aquellos tiempos, en que los conquistadores sabían matar mejor que vivir. Sólo un compañero de Pizarro, Mansio Sierra Leguizama, falleció de enfermedad en la cama, los demás perecieron por la espada o la soga. Lo mismo pasaba con los indios, que aunque mayores en número, se encontraban en inferioridad de condiciones. Las expectativas de vida no superaban los 40 años.

Durante muchos años en España y sus colonias, el confesor estaba muchos antes que el médico de cabecera. Ello mismo hace poco probable que Don Pedro de Valdivia haya sido el fundador del Hospital del Socorro, hoy deno- minado San Juan de Dios. No, la época aquella era ajena a cosas de misericordia y humanidad. Es más probable que Doña Inés de Suárez, le hubiese insinuado a Don Pedro la necesidad de un primer hospital en Chile. Aunque, a decir de la época parece haber sido un particular avecindado en Chile, quien tuvo el meritorio acto.

La verdad es que la malagueña doña Inés de Suárez fue el primer médico, la primera cirujano y posiblemente la primera pediatra de Santiago de Chile. ¿Será por ello que hay un médico potencial detrás de cada mujer en Chile, dispuesta a hacer sus propios diagnósticos e incluso tratamientos? Menudo intercambio científico en la primera etapa de la conquista debe haber sido el que se produjo entre los indígenas y doña Inés. Más de alguna Junta médica en el Chile incipiente, debe haber surgido entre conquistadores e indígenas machis, quienes se ufanaban de poseer un importante herbolario terapéutico. Los aborígenes le entregaron a doña Inés las primeras nociones de las bondades de la raspadura del palqui, el natri y sus hojas refrigerantes, aunque ignoraban (por ser las primeras importaciones no tradicionales) cualquier cosa relativa al cólera y la viruela. Tenían claras nociones de la sarna (pitra o alhuépitu), la hernia o paguacha, la demencia o pual e incluso efectuaban sus juntas médicas o thavmun. Aún hoy solemos escuchar a más de algún colega, que sin conocer el origen del término, menciona una "paguacha" refiriéndose a un aumento de volumen abdominal. 
Los machis, primeros médicos de la región, curaban con ritos bárbaros y supersticiosos, contorsiones diabólicas y mentiras, para expulsar del cuerpo afligido el mal o ivum. Llamaban chavalonco a todas las fiebres, por el sopor que producen en el paciente, vocablo derivado de chavo (modorra) y lonco (cabeza). Numerosa cantidad de hierbas permitían a los indígenas resolver las distintas dolencias, destacando entre ellas la corteza del avellano, la hierba llantén, la murta y el maqui como astringentes, las hojas y los cogollos del ral ral y del pelu como purgantes, el hinojo y el mileu como diuréticos (después se agregaría el pelo de choclo). De acuerdo a los escritos del Padre Diego de Rosales, la reina de las hierbas medicinales en Chile correspondería al quinchamalí, nombre original de un famoso cacique de lo que hoy corresponde a la Región Metropolitana. Hasta hace pocos años, a los servicios de urgencia llegaban los niños intoxicados por chamico o miaya (cuyos signos correspondían a una potente acción parecida a la marihuana y también en otro de sus componentes a la cocaína), muy utilizado en la época colonial por ser un admirable narcótico consumido por los delincuentes que iban al patíbulo, para aliviar el dolor de la muerte.

Ya en 1577, Santiago alcanzaba a los mil habitantes y los primeros esfuerzos médicos de Doña Inés, fueron reemplazados por varios otros "facultativos", entre quienes destaca el Licenciado Castro, el Bachiller Bazán, el licenciado Alonso del Castillo (tercer facultativo de la colonia), quien tiene el gran mérito de haber sugerido traer el agua de la quebrada de Tobalahua (hoy De Ramón) para la bebida y preparación de alimentos con menor riesgo sanitario. Aunque no ha sido catalogado de un acto meritorio, el Bachiller Bazán se hizo cargo de la muerte del segundo Gobernador de Chile, Don Francisco de Villagra a los 56 años de edad, hecho denostado por el flamante Procurador de la época, Don Alonso de Córdoba.

Pocos años después empiezan a integrarse, los denominados hoy en día, profesionales de colaboración médica, entre ellos inicialmente las matronas y los farmacéuticos. Algunos de ellos provenientes del Perú. Virreinato que en esos tiempos abastecía a sus países vecinos de profesionales con una sólida formación.

\section{Mientras tanto, ¿qué sucedía con la Pediatría?}

En la cultura aborigen, terminado el parto en la conocida posición en cuclillas y en pleno monte, había especial preocupación por el examen clínico del recién nacido, buscando malformaciones y signos de debilitamiento precoz, causa de marginación social. La mentalidad guerrera predominaba claramente en los neonatólogos aborígenes.

El Padre D. Rosales destaca en uno de sus capítulos (De la crianza de los hijos para que se hagan fuertes i diligentes) la preocupación de los indígenas para que sus niños crecieran fuertes y sanos, a través de la actividad física y una alimentación saludable, pobre en sal y en algunos casos recurriendo precozmente a la sangría. Ello permitía evitar la obesidad, denominando a los gordos de aquellos tiempos como mothilones. Notable y futurista visión de los mapuches, aunque la estatura no era su preocupación fundamental. Tampoco hay estudios disponibles que señalen que su dieta era carente en zinc. Sí tenían especial preocupación por su aspecto físico, especialmente desarrollo muscular, que los haría eficientes para sus guerras. Recurrían a la crianza a la intemperie, incitaban a los niños a desafiar obstáculos naturales y a marchar grandes distancias.

La limeña Isabel Bravo, que había sido declarada "hábil y suficiente" por el protomedicato de Lima, y que arribó a Valparaíso alrededor de 1560, habría sido la primera partera en la época colonial y su vivienda se ubicaba en la rivera del río Mapocho. Algunos años después se reconoce como "partera" a Elena Roldón.

Graves problemas de abastecimiento de agua causaban estragos en la población. La pésima costumbre de usar agua del río Mapocho para bebida y preparación de alimentos, se acompañaba de brotes frecuentes de diarrea y enfermedades transmisibles infecciosas epidémicas (cólera, sarampión, tuberculosis, sífilis, tos convulsiva). Muchos años debieron transcurrir para convencer a los santiaguinos de las bondades del uso de las aguas de Tobalaba y la quebrada de Ramón. De hecho fue recomendado en 1547 y no fue bien aprovechado por la población hasta 200 años después. Al pésimo 
saneamiento básico se agregaba la vivienda, antihigiénica, mal ventilada, con escasa iluminación y alto grado de hacinamiento humano y convivencia con otros animales.

Como ha sucedido muchas veces en el transcurso de la humanidad, los niños han permitido el enriquecimiento ilícito de muchos. Existía el cargo de "Defensor de Menores", desempeñado por favoritos del gobierno de turno, quienes en muchas oportunidades aducían la protección de menores para hacer fortuna.

Durante la colonia, la escasa preocupación por la salud infantil era la tónica. No sólo en Chile sino en la mayoría de los países de América Latina. Ello a pesar que en Europa ya surgían los hospitales infantiles, el primero de ellos en Francia (Hospital Enfant Jesús). Así, a fines de la colonia, la tasa de mortalidad infantil informada en Chile era de 330 por mil $\mathrm{RN}$ vivos (ver gráfico). Sin embargo, con el transcurso del último siglo, dicha tasa se redujo en forma extraordinaria, llegando a constituir junto con Cuba y Costa Rica, las tasas más bajas de América Latina.

\section{Disminución de la mortalidad infantil}

La información disponible señala una disminución sostenida de la tasa de Mortalidad Infantil en Chile, de 330 niños menores de un año por mil RN vivos en 1906 a menos de 8 por mil RN vivos el año 2006, lo que corresponde a un descenso de $98 \%$ en la centuria analizada. Al observar la mortalidad infantil, el análisis destaca que a nivel mundial, Japón (con 3,5 defunciones de menores de un año por mil nacidos vivos) continúa siendo el país que en el mundo presenta mejores condiciones respecto al número de muertes de recién nacidos evitadas. En América Latina, este indicador favorece a Cuba cuya cifra informada para el año 2008 alcanza a 4,7 fallecidos por mil RN vivos, explicado por afecciones perinatales, anomalías congénitas e infecciones. La situación de más alta mortalidad infantil en el mundo se presenta en Sierra Leona, África con 200 por mil. En América Latina los niños de Haití son los que al nacer se encuentran en la situación más desfavorable $(59,1$ por mil), de acuerdo con la información disponible de la Organización Mundial de la Salud (figura 1).

\section{Inicios de la Pediatría en Chile}

Trascendentales cambios se han observado en el desarrollo de la Pediatría, desde que inicialmente, al menos en Chile, los grandes temas pediátricos, particularmente en lo académico, se circunscribían a no más allá de tres o cuatro enfermedades. Notables avances se han observado en importantes temas: disminución de la mortalidad infantil, desaparición de enfermedades infectocontagiosas como viruela, poliomielitis, difteria, sarampión. El último caso de poliomielitis por virus salvaje en América se

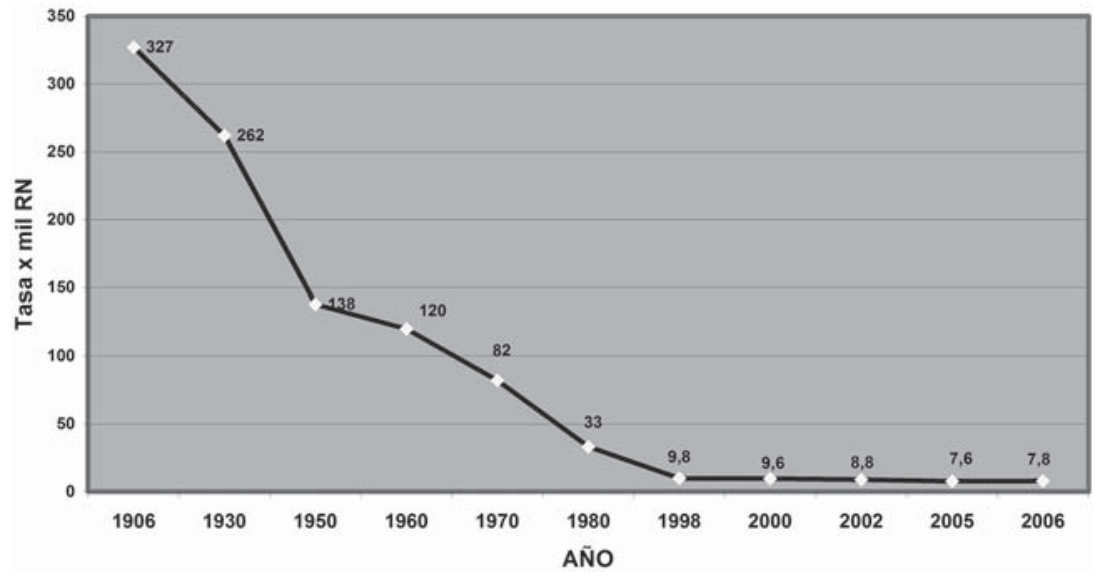

Figura 1. Tasa de mortalidad infantil (Chile 1906-2006). 
observó en 1990 en la sierra de Perú. Lo mismo ha podido observarse en desnutrición, aunque en Chile, la ley del péndulo ha llevado realmente al otro extremo.

En la naciente Facultad de Medicina de la Universidad de Chile, se hacían esfuerzos por motivar a los estudiantes de medicina en el aprendizaje de las enfermedades de la infancia. Se solicitó al Profesor Jaime Tocornal Grez exponer algunas enfermedades de niños, fundamentalmente Difteria, Asma y Epilepsia. En 1890, se encargó al Dr. Roberto del Río Soto Aguilar, recientemente llegado de Europa, la primera Cátedra de Enfermedades de Niños. A sus clases dictadas en el Hospital San Vicente de Paul y que tenían el carácter de asistencia voluntaria, no llegaban más de 5 alumnos. Ello revelaba el escaso interés que despertaba la pediatría en aquellos tiempos, a pesar que la mortalidad infantil estimada superaba los 360 por mil recién nacidos vivos.

Iniciada la Pediatría por interés primordial de los Drs. Francisco Javier Tocornal Grez y Roberto del Río Soto Aguilar, poco a poco, incluso a pesar de los internistas, fue ganando un merecido espacio dentro de las especialidades y particularmente de la investigación científica. Esta, impulsada en sus inicios por el Profesor Alfredo Commentz Loeffler, llegó posteriormente a ser reconocida en América Latina, especialmente por sus logros en Salud Pública y la investigación clínica liderada por los Drs. Julio Meneghello Rivera en deshidratación y alteraciones hidroelectrolíticas y Fernando Monckeberg Barros en desnutrición.

El 16 de Enero de 1901, surge el "Hospital de Niños de la Calle Matucana". Diez años después se funda un segundo hospital destinado a la población del sector sur de Santiago. Por iniciativa de la Junta Central de Beneficencia se acordó dar el nombre de Hospital Dr. Roberto del Río Soto Aguilar al primer hospital de niños del país y Manuel Arriarán Barros al construido en el Área Sur, que había comenzado tímidamente a funcionar por allá por 1913. Ambos próceres junto con el Dr. Emilio Commentz Loeffler fueron grandes impulsores de la salud del niño en nuestro país. Los mismos terrenos permitieron, con el empuje del Dr. Cesar Izzo Parodi, crear el primer Servicio de
Urgencia Infantil de Sudamérica, cuyo funcionamiento se inicia el 2 de enero de 1942. Debe agregarse a Heinrich Finkelstein, destacado pediatra alemán, quien en sus diez años en Chile impulsó y marcó las características del desarrollo de la pediatría en Chile. Aún quedan improntas de su rígido carácter y disciplina.

\section{¿Qué se espera del pediatra hoy en Chile?}

\section{Compromiso con la salud del niño, su familia, su entorno social y medioambiental}

Hoy día tarea difícil, dada la preponderancia del mercado y su patología inherente en el comportamiento humano, caracterizada por crisis de identidad y pérdida de compromiso. Sin embargo, al recordar a nuestros antiguos maestros y su alto grado de compromiso, al igual que muchos ignorados pediatras, pensamos como fueron capaces de enfrentar la titánica tarea de resolver la patología preponderante en la infancia de aquellos tiempos.

\section{Restablecer el mayor grado de comunicación con el niño y su familia y la mejor relación médico/paciente}

En la actualidad, el médico se ha transformado en un mero "dispensador biotecnológico", a veces impersonal, casi ausente. Las deficiencias observadas en la historia clínica, examen físico y la escasa comunicación establecida, son el caldo de cultivo de los conflictos y demandas judiciales observadas hoy en la práctica clínica. Esta incomunicación se ha relacionado con la reaparición de medicinas alternativas o sintergéticas, rama de la medicina que ha surgido con fuerza en el mundo y también en nuestro país.

\section{Compromiso con la clínica, la investigación y la medicina basada en la evidencia}

La destreza y el entrenamiento clínico es la única ventaja comparativa del desempeño médico en un país subdesarrollado. Los mayores errores diagnósticos se han originado en una mala historia clínica o examen físico poco exhaustivo. La investigación clínica, no necesariamente de alto costo, ha permitido superar 
paradigmas y verdades asumidas como tales, sin mayor base científica. La medicina basada en evidencias es nuestra mejor defensa frente a dificultades médico-legales. Sin embargo, en algunas oportunidades hemos asistido a la tiranía de las evidencia, olvidando que la medicina tiene mucho de arte e incluso que a veces la evidencia es enemiga de la prudencia. Los avances en técnicas diagnósticas de laboratorio e imágenes permiten una rápida precisión diagnóstica en muchas patologías. El contacto con laboratorios internacionales y Centros diagnósticos de alta complejidad es rápido y expedito, aunque de alto costo. Tardíamente percibimos que la capacidad de la familia de absorber el costo de los exámenes para un diagnóstico preciso es mayor de la que habíamos presumido. Se ha insistido mucho en el verdadero rol del médico, evitando asumir economías malentendidas.

\section{Fomento del rol educativo y de prevención primaria}

Hay interesantes iniciativas de educación grupal, con grupos objetivos, en instituciones públicas y privadas e incluso en consultas privadas. Ello cobra su máxima trascendencia en prevención de riesgos y accidentes, del sobrepeso, obesidad y en patologías relacionadas con trastornos del ánimo y conductas de riesgo en enfermedades adictivas.

Actualmente, uno de los mayores impactos en la prevención de enfermedades se deriva de la incorporación de ácido fólico en la alimentación de los chilenos, con una experiencia similar a Estados Unidos y Canadá. En efecto, desde que el $1^{\circ}$ de enero del año 2000, por disposición del Ministerio de Salud, se está fortificando la harina de trigo usada en Chile para la fabricación de pan y otros alimentos con 220 microgramos de ácido fólico por cada 100 gramos de harina, se ha observado una disminución del $51,9 \%$ de los defectos del tubo neural, $66 \%$ de reducción de la espina bífida aislada y $42 \%$ para la anencefalia. Incluso se ha planteado la posible relación con disminución de otras malformaciones congénitas como cardiovasculares, nefrourinarios, labio y paladar hendidos. Aunque existen algunas evidencias que sugieren un aumento de la incidencia de cáncer colorectal. Por ello, dicha fortificación tiene su máximo valor en el período preconcepcional y primeras 12 a 16 semanas de embarazo.

\section{Contribuir al óptimo cumplimiento del Programa Ampliado de Inmunizaciones (PAI) o Programa Nacional de Inmunizaciones (PNI)}

El Programa de vacunas en el Chile de hoy puede y debe ser optimizado. Es imprescindible e impostergable enfrentar el tema de vacunas con criterio moderno, particularmente en vacunas de incorporación reciente (pertussis acelular, polio inactivada, varicela, hepatitis, neumococo conjugado, rotavirus, papiloma virus humano) ya disponibles en Chile, aceptando que aún es un tema sujeto a controversia. Debe agregarse programas especiales de vacunación para el paciente de riesgo (prematuros, inmunodeficiencias, oncológicos, fibrosis quística) y su entorno familiar y programas oportunos para el niño que viaja. En un futuro próximo es posible que se incluya virus sincicial respiratorio, adenovirus y meningococo grupo B. La varicela, el coqueluche y la neumonía, son causas importantes de muerte por enfermedad inmunoprevenible. En breve plazo, a las vacunas heptavalente conjugada $\left(\right.$ Prevenar $^{\circledR}$ ) y 23 valente polisacárida (Neumovax ${ }^{\circledR}$ o Pneumo $23^{\circledR}$ ) se agregará la conjugada diez valente y 13 valente. Infanrix hexa ${ }^{\circledR}$ (laboratorios GSK) vacuna disponible en Chile y Hexavac ${ }^{\circledR}$ (laboratorios AP), pueden ser utilizadas en pacientes con riesgo de síndrome convulsivo o cuando la condición económica lo permite. Sus modificaciones en relación al PNI (DPT- Hib; Hb; Polio oral trivalente) incluyen pertussis acelular, polio a virus muerto. Particularmente, las vacunas con pertussis acelular, disminuye significativamente el riesgo de reacciones adversas (fiebre, irritabilidad, convulsiones). Con alguna frecuencia el pediatra supone que la familia no podrá asumir el costo de estas vacunas, sin embargo, suele ser posible.

\section{Profundizar el rol del pediatra y especialista}

Importante rol cabe aquí a las instituciones universitarias. El médico pediatra debe tener claros criterios de derivación a especialista, con el mejor sistema de referencia y contra referencia. Es probable que además de los médicos 
pediatras generales especialistas en atención ambulatoria, se requiera especialistas en atención cerrada (clínica u hospital), con mayor entrenamiento en enfermedades agudas con falla multisistémica y descompensación de enfermedades crónicas, que complementen la labor de los intensivistas. Agrava dicha situación el enclaustramiento actual de las instituciones universitarias y su rápida expansión mundial en término de alumnos matriculados (de 28 millones en 1970 a 63 millones la primera década del 2000). En Chile, las escuelas de medicina se han triplicado. Mayor dificultad genera aún la falta de campos clínicos acreditados, marginación de docentes calificados y la mínima participación del sector productivo en su financiamiento. Se agrega a ello el surgimiento de nuevos profesionales muy endeudados, lo que induce a postergar su perfeccionamiento o deteriora su calidad e incluso pone en riesgo la ética en su desempeño.

\section{Telemedicina}

Incorporar la biotecnología, la informática, las redes de Internet, las redes de comunicación e información y los nuevos métodos de aprendizaje, comunicación y resolución de problemas vía electrónica (video conferencia, video diagnóstico diferencial y terapéutico). Se ha hecho una sana costumbre en los centros privados más avanzados la entrega de resultados de imágenes y exámenes "on line", lo que facilita la oportunidad diagnóstica y terapéutica local y por telemedicina. En el sistema público se ha efectuado una gran inversión con resultados aún incipientes. Con frecuencia creciente los padres de nuestros niños en control llegan con información obtenida a través de páginas web, lo que obliga al pediatra a mantenerse muy al día en el conocimiento. Sin embargo, esta información puede ser obtenida de fuentes inadecuadas o el procesamiento de ella por los padres podría ser sesgado, lo que induce a generar falsas expectativas terapéuticas y de pronóstico.

\section{Niños y Adolescentes con Necesidades Especiales de Atención en Salud}

La prevalencia de enfermedades crónicas ha aumentado fundamentalmente por la mayor sobrevida de niños con afección congénita o crónica lo que resulta en una concentración creciente de morbilidad y mortalidad asociada a este grupo de niños, los cuales absorben un alto porcentaje del gasto en salud. La OMS estima que para el año 2020 el $60 \%$ del gasto en salud corresponderá a patología crónica.

Se calcula que $10 \%$ de la población mundial sufre de alguna discapacidad física o psíquica. En Chile, se han realizado recientemente dos estudios que objetivan ésta realidad: el primer Estudio Nacional de Discapacidad (ENDISC2004) realizado en el año 2004 por el Instituto Nacional de Estadisticas (INE) y el Fondo Nacional de la Discapacidad (Fonadis), estima en un $12,9 \%$ la prevalencia en la población nacional ( 1 de cada 8 chilenos) y de éstos $5,7 \%$ o sea 1 de cada 31 personas discapacitadas corresponde a población menor de 15 años. Otro estudio relacionado con la II Encuesta de Calidad de Vida y Salud realizada por el Ministerio de Salud y el INE en el año 2006 nos da por primera vez información acerca de la prevalencia de patología crónica en menores de 15 años. Estos resultados muestran que la mayor prevalencia corresponde a $15,7 \%$ para enfermedad respiratoria crónica, $8,9 \%$ problemas de visión, 7\% problemas de piel por más de 6 meses, $5,6 \%$ prematuros $5,2 \%$ otro problema crónico, 4,6\% trastorno de déficit atencional.

Chile, junto a Costa Rica y Cuba, se sitúa entre los tres países con la esperanza de vida más alta de América Latina, de acuerdo con el primer estudio del Instituto Nacional de Estadísticas del Siglo XXI sobre mortalidad y esperanza de vida en el país. De acuerdo a las primeras Tablas de Mortalidad del Siglo XXI, elaboradas por el Instituto Nacional de Estadística a partir del Censo 2002 y de los hechos vitales de nacimientos y defunciones de los años 2001 y 2002, la esperanza de vida al nacer del período 2001-2002 es de 80,4 años para las mujeres y de 74,4 años para los hombres. Es probable que para el año 2010 dicha cifra mejore aún en tres años de sobrevida adicionales.

En nuestro país, la esperanza de vida más alta al nacer se sitúa en Coquimbo. Si bien no se observan brechas muy significativas a lo largo del país, según los indicadores demográficos prevalentes en los años 2001 y 2002, las 
expectativas de vida al nacer en las regiones de Coquimbo y Metropolitana alcanzan en promedio 78,43 y 77,86 años, respectivamente, siendo las más altas en todo el país. En contraposición, las regiones de Antofagasta y de Magallanes figuran con la menor esperanza de vida al nacer, con 75,33 años y 75,73 años, respectivamente.

El Índice de Desarrollo Humano (IDH) fue elaborado por el Programa de las Naciones Unidas para el Desarrollo (PNUD) en 1990 como una alternativa a la clasificación del progreso de los países sólo en base al nivel de su Producto Interno Bruto. El índice del PNUD en cambio, sintetiza el nivel de logro en tres dimensiones: salud, educación e ingresos. (Fuente: PNUD Informe socre Desarrollo Humano Mundial, 2005). Chile ha experimentado un aumento progresivo del IDH, con valores de $0,74,0,785$ y 0,854 en los años 1975,1990 y 2003 , respectivamente; siendo considerado de alto nivel de IDH un valor sobre 0,8 .

Sin embargo, dentro de los países con alto IDH, Chile posee el triste record de mayor índice de desigualdad o inequidad. El 10\% de la población más rica del país acapara el $47 \%$ de los ingresos. Ha llegado a ser el país de América latina con mayor ingreso anual per cápita (aproximadamente 15.000 dólares), pero con el mayor índice de cesantía juvenil. Dicha combinación de factores es parte de la explicación de la violencia en sus distintas manifestaciones instalada en el país.

Tal vez la pregunta crucial hoy en día, en que se ha duplicado la esperanza de vida al nacer, no es cuanto se va a vivir, sino como se va a vivir con estas nuevas expectativas.

\section{Impulsar los "procedimientos de Screening”}

La búsqueda sistemática de displasia de caderas por radiología convencional y por ultrasonografía (que puede anticipar el diagnóstico y tratamiento con menos efectos adversos), hipotiroidismo, fenilketonuria, u otros como el "Screening neonatal ampliado" ya disponible en Chile, examen que se efectúa en el Instituto de Nutrición y Tecnología de los Alimentos (INTA) y que introduce capacidad diagnóstica en: medición de fenilalanina (PKU), perfil de aminoácidos y de acylcarnitinas por técnica de Espectrometría de Masa en Tandem; hormona tiroestimulante (TSH); biotinidasa (déficit de biotinidasa); 17 hidroxiprogesterona para pesquisa de hiperplasia suprarrenal congénita; galactosa total por técnica colorimétrica; galactosa 1 P-Uridintransferasa (galactosemia); tripsina inmunoreactiva por técnica fluorométrica (screening inicial para fibrosis quística).

También está disponible el Programa IVX (Geno Metabolic Screening) para el recién nacido y lactante menor de dos meses, a través del Laboratorio Chile y su contacto vía aérea diaria por courier a Pediatrix (EE.UU.), examen que agrega entre otros estudios al screening neonatal ampliado: deficiencia de Glucosa 6 Fosfato Deshidrogenasa, Enfermedad de Células Falciformes, otras Hemoglobinopatías y estudio complementario de deficiencia de Galactokinasa y Galactosa-4 Epimerasa. En caso de resultados positivos, consultores genéticos disponibles los 365 días del año se contactarán con el médico tratante. Lo anterior está permitiendo un diagnóstico cada vez más oportuno de este tipo de enfermedades, lo que ha contribuido a mejorar su pronóstico y disminuir significativamente el costo del tratamiento y sus secuelas. Persisten dificultades en la interpretación de los resultados, por la existencia de falsos positivos y portadores, por lo cual es indispensable contar con asesoría especializada. Debe intensificarse aún la pesquisa oportuna de otras enfermedades, tales como defectos ocultos de tubo neural, efectos adversos de alcohol y consumo de drogas, síndrome metabólico e incluso diabetes. En países de alta incidencia (Japón), se agrega screening para neuroblastoma e incluso búsqueda de defectos de tubo neural. De hecho, en fibrosis quística (enfermedad genética letal más frecuente en caucásicos, con una incidencia en Chile de 1 x $8000 \mathrm{RN}$ vivos) en un estudio reciente en nuestro país, pudo demostrarse que el promedio de edad diagnóstica fue de 6 años 11 meses hasta el 2005 y desde el año 2006 bajó a 5 años 1 mes. Todavía se observan diagnósticos innecesariamente tardíos, lo que ensombrece el pronóstico. En los países desarrollados la edad diagnóstica es muy inferior, en base a Programas Nacionales de Detección Precoz altamente eficientes, ya dispo- 
nibles en Chile, para grupos de mayor solvencia económica. Los estudios al respecto ya han demostrado las ventajas en la relación costobeneficio. Hoy en día rara vez vemos diagnósticos tardíos de luxación inveterada de caderas, cretinismo, idiocía fenil pirúvica, diarrea intratable, habiendo incluso desaparecido dichas denominaciones. Los diagnósticos de diabetes mellitus, fibrosis quística, síndrome de alcohol fetal, enfermedades metabólicas, peroxisomales, defectos de beta oxidación, son más oportunos, aumentando la sobrevida pero produciendo a la vez un incremento progresivo de pacientes con enfermedades crónicas, preocupando su cali- dad de vida y su consejo genético. Sin embargo, no estamos poniendo el mismo énfasis en la pesquisa precoz de los trastornos del ánimo y conductas de riesgo, observando a veces que el intento de suicidio y las solicitudes de auxilio no fueron adecuada y oportunamente valoradas.

"Importante rol le cabe al pediatra hoy día. Debemos asumir nuestra contribución en la infancia para lograr años de vida saludable en el ser humano hasta los ochenta y más años e intentar al menos en salud infantil, contribuir a evitar las brechas de inequidad". 